\title{
Quality of life and mortality in the general population: a systematic review and meta- analysis
}

Aung Zaw Zaw Phyo ${ }^{1}$, Rosanne Freak-Poli ${ }^{1,2}$, Heather Craig ${ }^{1}$, Danijela Gasevic ${ }^{1,3}$, Nigel P. Stocks ${ }^{4}$, David A. Gonzalez-Chica ${ }^{4,5}$ and Joanne Ryan ${ }^{1,6^{*}}$ (1)

\begin{abstract}
Background: Quality of life (QoL) is multi-dimensional concept of an individual' general well-being status in relation to their value, environment, cultural and social context in which they live. This study aimed to quantitatively synthesise available evidence on the association between QoL and mortality in the general population.

Methods: An electronic search was conducted using three bibliographic databases, MEDLINE, EMBASE and PsycINFO. Inclusion criteria were studies that assessed QoL using standardized tools and examined mortality risk in a non-patient population. Qualitative data synthesis and meta-analyses using a random-effects model were performed.

Results: Of 4184 articles identified, 47 were eligible for inclusion, involving approximately 1,200,000 participants. Studies were highly heterogeneous in terms of QoL measures, population characteristics and data analysis. In total, 43 studies (91.5\%) reported that better QoL was associated with lower mortality risk. The results of four metaanalyses indicated that higher health-related QoL (HRQoL) is associated with lower mortality risk, which was consistent for overall HRQoL (HR 0.633, 95\% Cl: 0.514 to 0.780), physical function (HR 0.987, 95\% Cl: 0.982 to 0.992), physical component score (OR 0.950, 95\% Cl: 0.935 to 0.965), and mental component score (OR 0.980, 95\% Cl: 0.969 to 0.992).

Conclusion: These findings provide evidence that better QoL/HRQoL was associated with lower mortality risk. The utility of these measures in predicting mortality risk indicates that they should be considered further as potential screening tools in general clinical practice, beyond the traditional objective measures such as body mass index and the results of laboratory tests.
\end{abstract}

Keywords: Quality of life, Life quality, Health-related quality of life, Mortality, Meta-analysis, Predictor, Review

\footnotetext{
* Correspondence: joanne.ryan@monash.edu

${ }^{1}$ School of Public Health and Preventive Medicine, Monash University, 99

Commercial Road, Melbourne, VIC 3004, Australia

${ }^{6}$ PSNREC, Univ Montpellier, INSERM, 34000 Montpellier, France

Full list of author information is available at the end of the article
}

(c) The Author(s). 2020 Open Access This article is licensed under a Creative Commons Attribution 4.0 International License, which permits use, sharing, adaptation, distribution and reproduction in any medium or format, as long as you give appropriate credit to the original author(s) and the source, provide a link to the Creative Commons licence, and indicate if changes were made. The images or other third party material in this article are included in the article's Creative Commons licence, unless indicated otherwise in a credit line to the material. If material is not included in the article's Creative Commons licence and your intended use is not permitted by statutory regulation or exceeds the permitted use, you will need to obtain permission directly from the copyright holder. To view a copy of this licence, visit http://creativecommons.org/licenses/by/4.0/ The Creative Commons Public Domain Dedication waiver (http://creativecommons.org/publicdomain/zero/1.0/) applies to the data made available in this article, unless otherwise stated in a credit line to the data. 


\section{Background}

Quality of life (QoL) is a multi-dimensional concept of an individual's general well-being status in relation to the value, environment, cultural and social context in which they live [1]. Since QoL measures outcomes beyond biological functioning and morbidity [2], it is recognised as an important measure of overall [1]. The origin of the term QoL dates back to the early 1970s, as a measure of wellness with linkage to health status like diseases or disability [3, 4]. Since then, interest in QoL has increased considerably [5]. As life expectancy increases, more emphasis has been placed on the importance of better QoL, and the maintenance of good health for as long as possible [6-9]. Indeed, global leading health organizations have emphasized the importance of QoL and well-being as a goal across all life stages [10-12].

Moreover, QoL has increasingly been used in the wider context to monitor the efficacy of health services (e.g. patient reported outcome measures, PROMs), to assess intervention outcomes, and as an indicator of unmet needs [13-15]. Several studies have reported that QoL is negatively associated with rehospitalization and death in patients with diseases such as coronary disease [16, 17], and pulmonary diseases [18]. Further, QoL is also predictive of overall survival in patients affected by cancer, chronic kidney disease or after coronary bypass graft surgery [19-22]. In recent years, an increasing number of studies have investigated whether QoL is also a predictor of mortality risk in the general population [23-27].

To date, there has been only one pooled analysis of eight heterogeneous-Finnish cohorts. That study of 3153 older adults, focused exclusively on the prognostic value of the validated 15-dimentional (15D) health-related QoL (HRQoL) measures [28] for predicting all-cause mortality [29]. However, there has been no systematic review investigating the association between QoL measured by different instruments and all-cause mortality in population-based samples which could be used to monitor health changes in the general population. A broad and comprehensive systematic review of the prognostic value of QoL for all-cause mortality prediction is needed to determine the utility of this QoL measure as a potential screening tool in general clinical practice. Therefore, this systematic review and meta-analysis was conducted with the aim of determining whether QoL is predictive of mortality in the general population which includes individuals with or without a range of health conditions.

\section{Methods}

\section{Search methods}

This systematic review and meta-analysis were conducted in accordance with the Preferred Reporting Items for Systematic Reviews and Meta-Analyses (PRISMA) statement [30]. The protocol for this review was registered with the International Prospective Register of Ongoing Systematic Reviews (PROSPERO) [31], under the registration number: CRD42019139994 [32]. The electronic bibliographic databases, MEDLINE, EMBASE and PsycINFO (through OVID) were searched from database inception until June 21, 2019. The search strategy was developed in consultation with a Senior Medical Librarian. The MeSH terms and key-words were developed for MEDLINE (through OVID) and were translated to EMBASE and PsycINFO using the OVID platform (See Supplementary Tables S1-S3, Additional File 1). When the full text of an article was not available, all attempts were made to obtain it by contacting the authors directly. To identify further potentially relevant studies, another search was also developed with those specific QoL / HRQoL measures which were found in this review (See Supplementary Table S4, Additional File 1). Additionally, the bibliography lists of the included articles were also hand searched.

\section{Inclusion and exclusion criteria}

Articles were included if they: (a) involved adults aged 18 years and older; (b) were general population-based samples with or without a range of health conditions; (c) assessed mortality from any cause or cause-specific mortality using a longitudinal design; and (d) included a QoL / HRQoL measure using a standard tool. QoL, the general well-being of individuals, consists of a range of contexts - health, education, employment, wealth, politics and the environment [33]. HRQoL, the self-perceived health status, includes physical, mental, emotional, and social domains [33]. We excluded papers not written in English, reviews, or studies including only specific groups of patients (e.g. patients on dialysis, those with fractures, after surgery, or individuals with a terminal illness).

\section{Study selection}

The screening of articles for eligibility according to title and abstract was undertaken independently by two reviewers (AZZP and $\mathrm{HC}$ ). All relevant full-text articles were independently reviewed by two reviewers (AZZP and $\mathrm{HC}$ ) for eligibility against inclusion criteria. The inter-coder reliability among two reviewers (AZZP and $\mathrm{HC}$ ) was $98 \%$. Discrepancies and disagreements between two reviewers (AZZP and $\mathrm{HC}$ ) were resolved through discussion with a third reviewer (JR). The screening process was undertaken using Covidence online software [34] and EndNote X9 software.

\section{Data extraction}

A standard data extraction form was used which included the following fields - title, authors, year of publication, setting/country, name of the study and design, 
sample size, follow-up period, participant characteristics (age and sex), specific QoL measure, cause of death (if available), and results (risk estimates including 95\% confidence intervals, CI) which were standardized in term of 1-unit increase or 1-SD increase for continuous risk estimate, or high vs. low for categorical risk estimates. The first reviewer (AZZP) completed the data extraction form and a second reviewer $(\mathrm{HC})$ verified the extracted information. All efforts were made to contact authors when there was missing information.

\section{Quality appraisal}

The quality of included studies was appraised using 'the Newcastle - Ottawa Quality Assessment Scale (NOS)' [35]. The NOS includes eight items, categorized into three dimensions (a) Selection, (b) Comparability, and (c) Outcome. The NOS scale uses a star system to evaluate the quality of each study, and they can be accredited a maximum of one star for each item within the Selection and Outcome dimension and two stars for the Comparability item. When considering the comparability of each study, a star was provided for studies which controlled for relevant covariates - age, sex (where appropriate), socioeconomic status or proxy (including socioeconomic position, education level or income), and some measure of co-morbidity (for example a specific health condition). An additional star was given for studies which considered other factors associated with QoL and mortality, including clinical measures, BMI, or lifestyle factors (i.e. smoking, alcohol, physical activity). The range of NOS scoring was from 0 to 9 stars, with higher scores indicating less susceptibility to bias. The methodological quality of included studies was rated by one reviewer (AZZP) and verified by a second reviewer (HC). Disagreements were resolved through discussion with a third reviewer (JR).

\section{Data synthesis}

The clinical and methodical heterogeneity of the studies was examined, in particular considering the measure of QoL used, and the effect estimates reported (Hazard Ratio (HR), Relative Risk (RR) or Odds Ratio (OR)). Where studies were considered too methodically heterogeneous to enable pooling, the results were summarized quantitatively in tables according to related categories with risk estimates; and 95\% CIs.

\section{Meta-analysis}

A meta-analysis was performed when there was a sufficient number of studies (four or more) which used the same domain of QoL measure and equivalent effect estimate parameters. In the present study, four metaanalyses were conducted for a pooled risk estimate of studies using (a) physical component score (PCS) of 36- item Short Form (SF-36) and OR / RR; (b) physical function domain of SF-36 and HR; (c) mental component score (MCS) of SF-36 and OR / RR; and (d) the 15-dimensional measure (15D) and HR. A DerSimonian-Laird random-effects model was chosen given heterogeneity in the studies in terms of population characteristics and varying health status. When more than one risk estimate was reported in the study, the fully adjusted/final regression model was included. In addition, when the included studies from the same cohorts with the same follow-up were eligible for metaanalysis, only one study with larger sample size was chosen for meta-analysis. Effect estimates were standardized where possible, so all values corresponded to a 1unit increase in SF-36 or a 1-SD increase in 15D (single index number). A pooled risk estimates of less than one indicates a decreased risk of mortality with higher QoL. Statistical heterogeneity was evaluated by using the $\mathrm{I}^{2}$ statistic, and the results were interpreted based on the Cochrane guidelines $(0-40 \%=$ no heterogeneity; $30-$ $60 \%=$ moderate heterogeneity; $50-90 \%=$ substantial heterogeneity; and $75-100 \%=$ considerable heterogeneity) [36]. In addition, when the $\mathrm{I}^{2}$ statistic showed considerable heterogeneity $(\geq 75 \%)$, the influence of individual studies on the pooled risk estimate was assessed using the metaninf command of STATA. Funnel plots and Egger's test were used to assess publication bias. Data analysis was undertaken using STATA statistical software, version 15.0 (StataCorpLP, College Station, TX, USA).

\section{Results}

\section{Search result}

A total of 4175 articles were identified from the systematic database search, and six additional articles were found via searching the reference list of included articles (Fig. 1). After removing duplicates, 3140 records remained for review. After title and abstract screening, 3058 articles were excluded and the full-text of the remaining 82 articles were evaluated for eligibility. A total of forty-four (44) articles met all inclusion criteria. Excluded articles with reasons for exclusion are presented in Supplementary Table S5, Additional File 1. Moreover, three articles from additional search were also added in this review. Therefore, a total of forty-seven (47) articles were included in this systematic review.

\section{Description of included studies}

Table 1 presents the characteristics of the 47 included studies. The earliest study was published in 1993 while the remaining included articles were published between 2002 and 2019, with 28\% published in the past 5 years. All studies except the retrospective cohort study of UlHaq et al., [75] were prospective cohort studies. The 


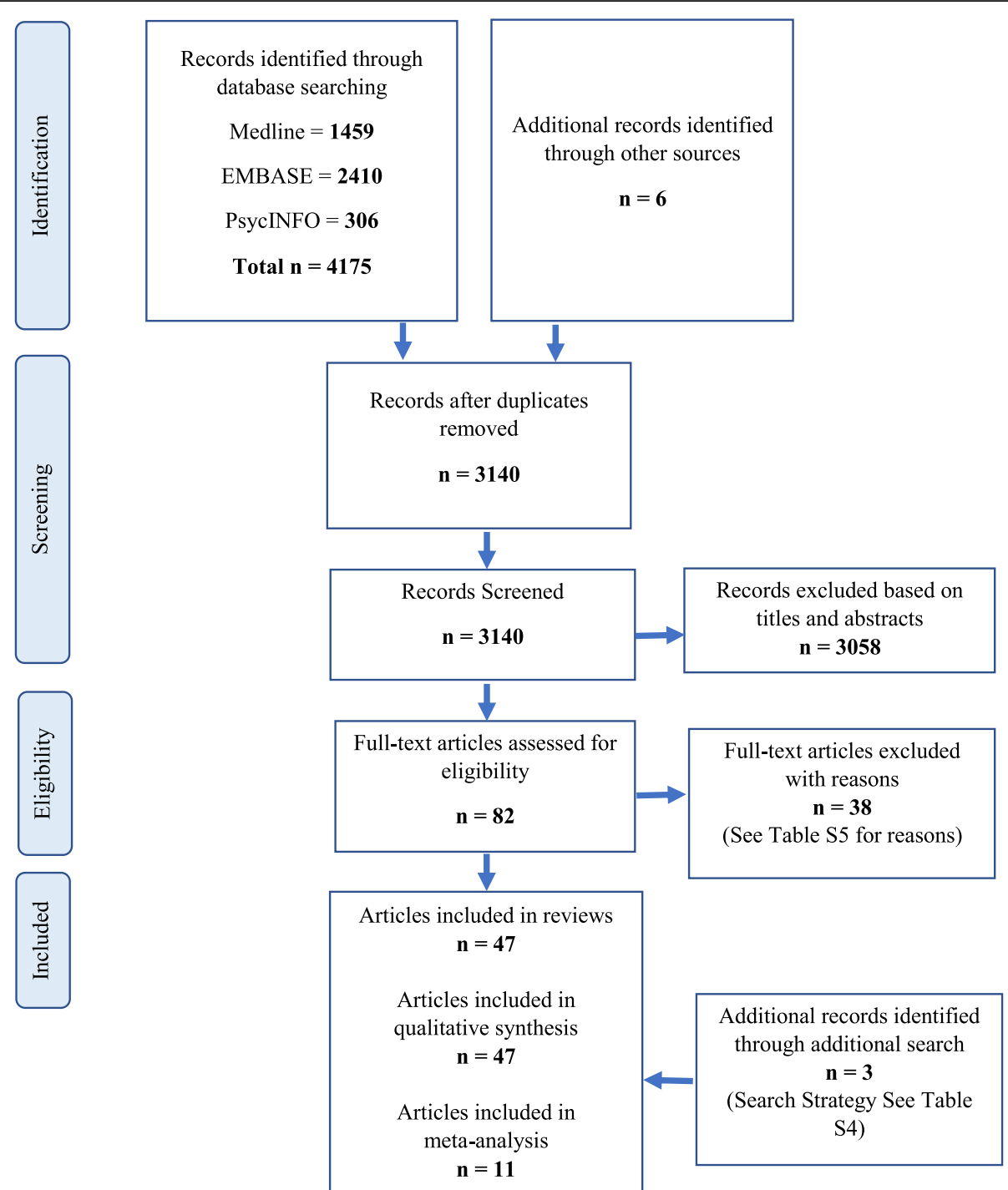

Fig. 1 Flow Diagram of Review Process

included studies were conducted in USA (34\%), UK (9\%), Australia (6\%), Canada (6\%), Spain (6\%), Taiwan (6\%), Belgium (4\%), Finland (4\%), Scotland (4\%), Sweden (4\%), Bangladesh (2\%), China (2\%), Germany (2\%), South Korea (2\%), Italy (2\%), Norway (2\%), and South Africa (2\%). The sample sizes of the included studies ranged from 171 [41] to 559,985 [40]; 14 studies had a sample size of less than 1000, 17 studies between 1000 and 10,000, 13 studies between 10 , 000 and 100,000 , and the remaining three studies [38, $40,53]$ has a sample size of more than 100,000 participants. Five studies included only males $[41,42,54$, $71,73]$ and three studies only females [56, 59, 74]. The remaining 39 studies recruited between 3 to $78 \%$ of women. The follow-up periods of the studies varied between 9 months [72] and 18 years [73].
This review included a variety of different QoL measures and half of the included studies (24 studies) measured QoL using the Short Form 36 (SF-36) (Tables 1 and 2). Of the 47 articles included in this review (Table 1 ), some studies involved the same cohorts and, in several cases, likely the same participants. Subsequent publications often reported effect estimates over different lengths of follow-up or using different QoL tools. Two published articles of De Buyser et al. reported the results of the same population-based cohort study [41, 42], three published articles by De Salvo et al. and Fan et al. were from the same study and included participants enrolled in the Veterans Affairs Ambulatory Care Quality Improvement Project [24, 43, 47], two published studies of Mold et al. and Lawler et al. used the same community-dwelling cohort $[57,61]$, two published 


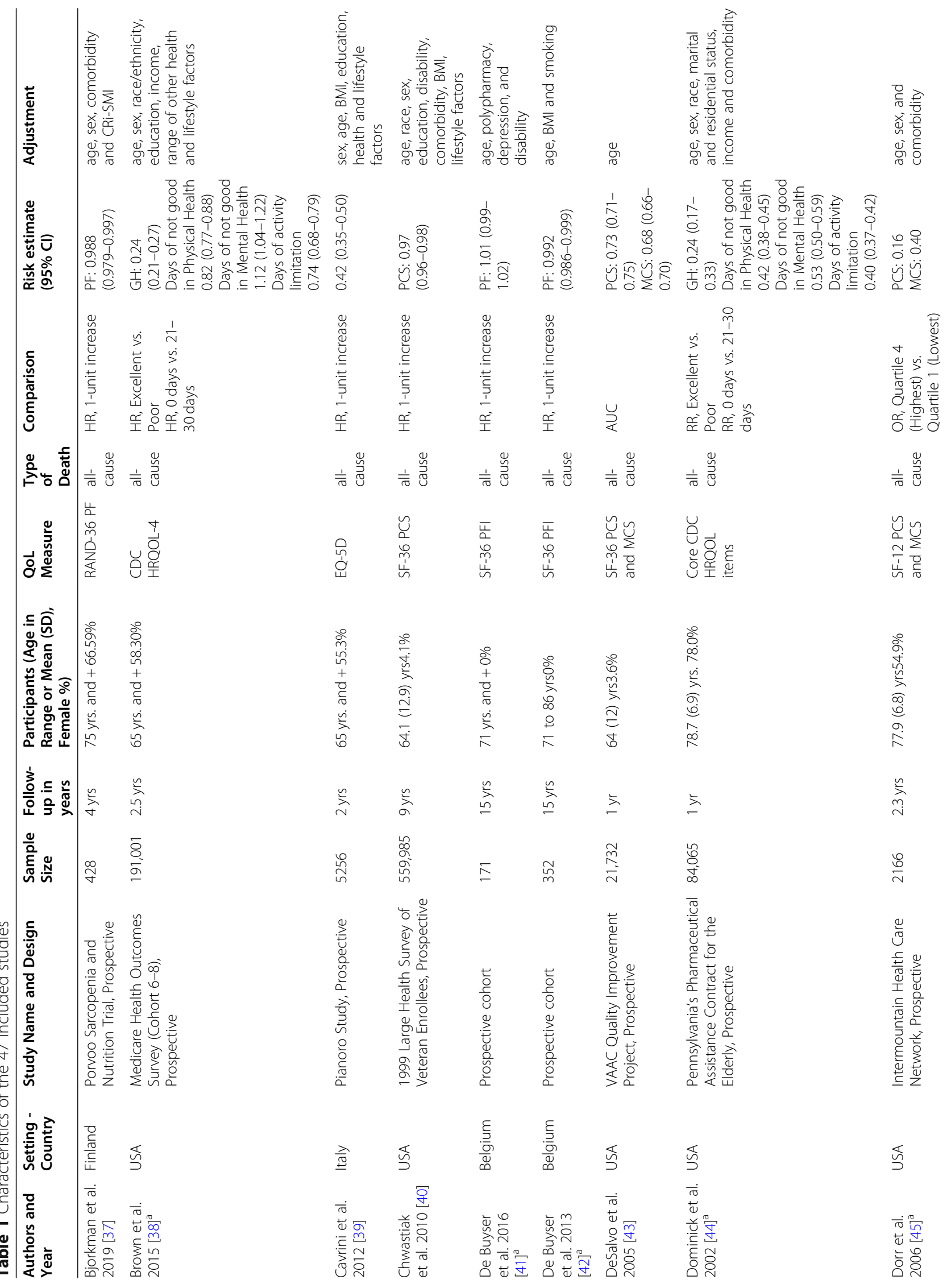




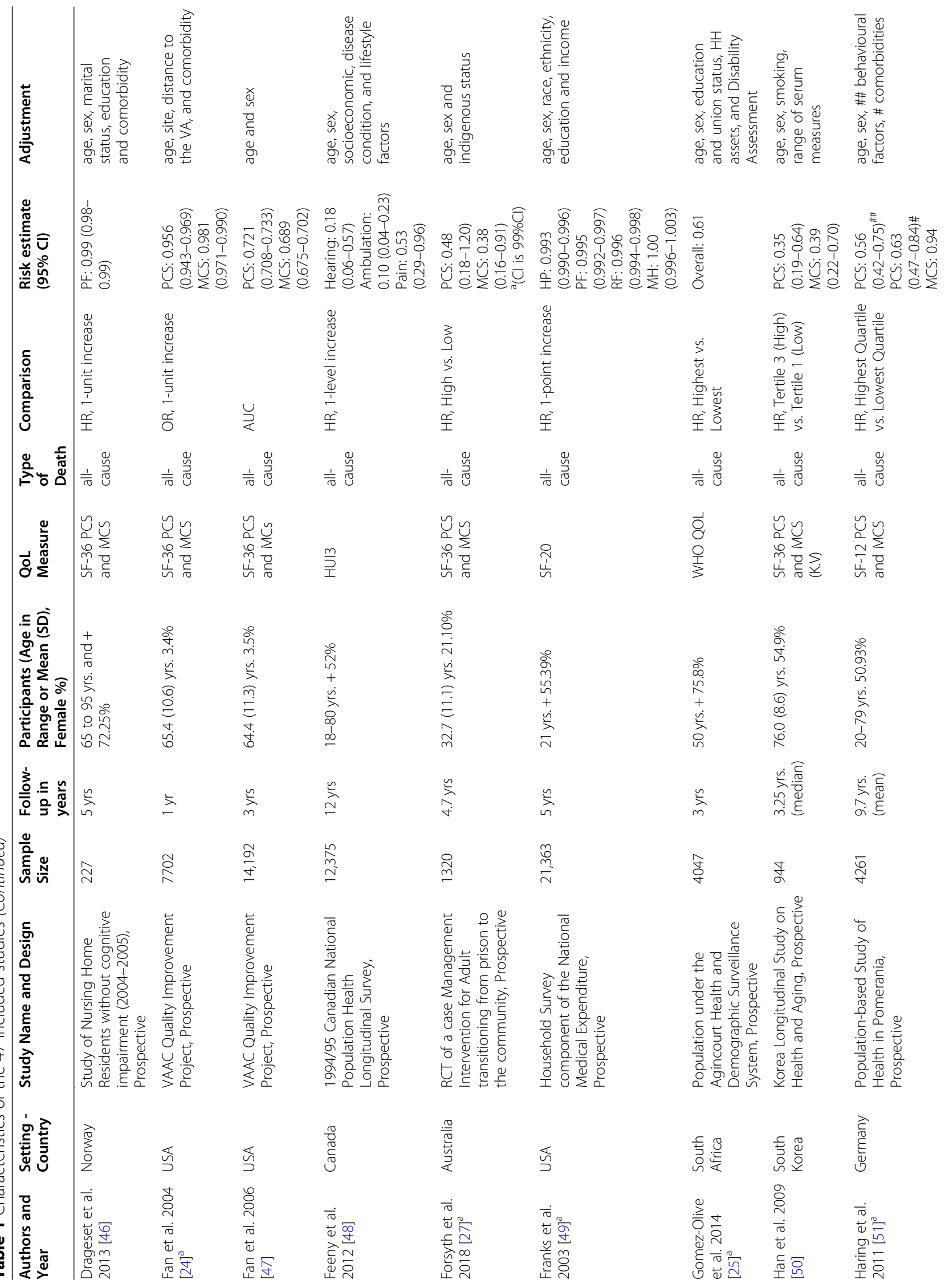




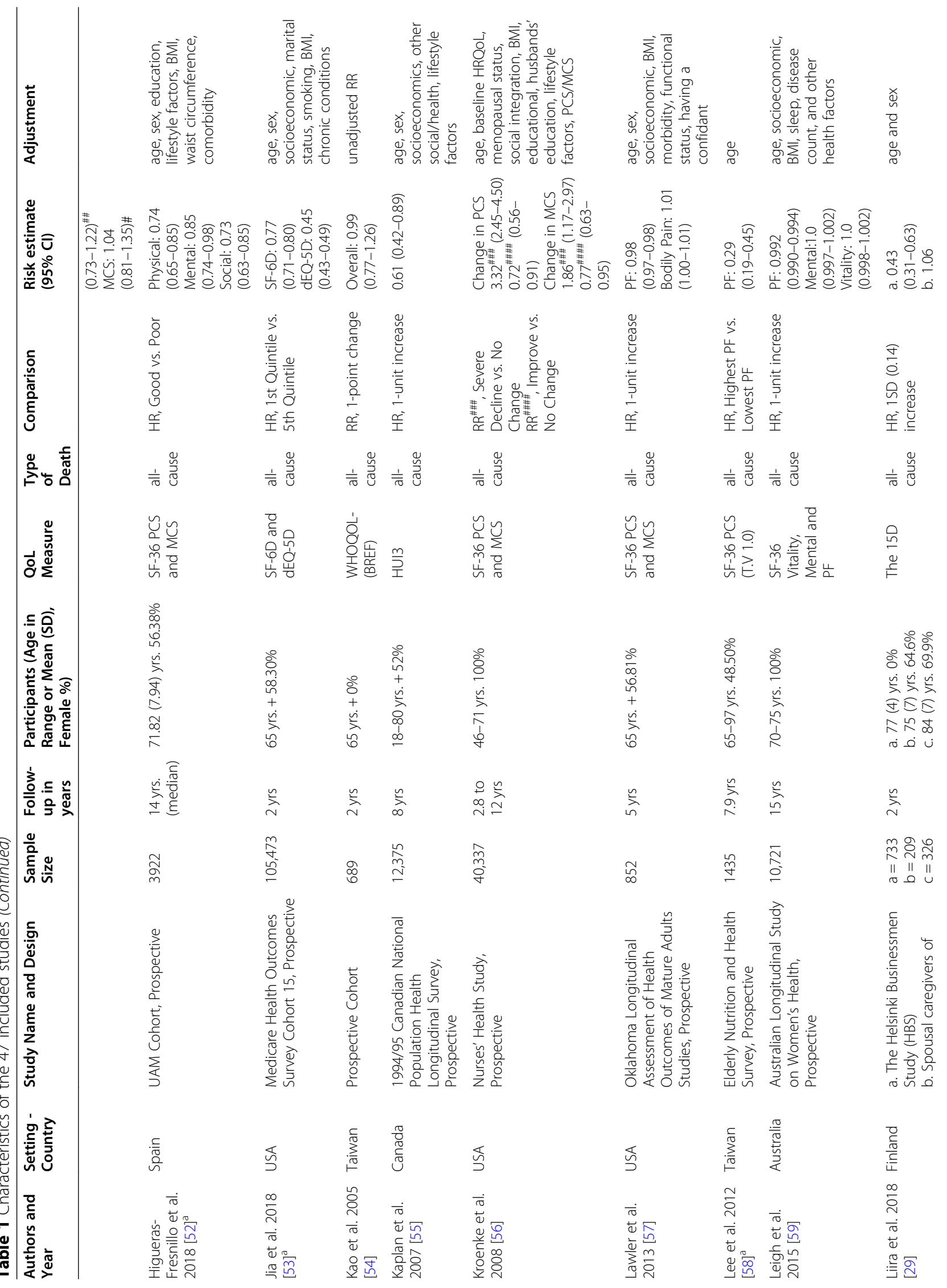




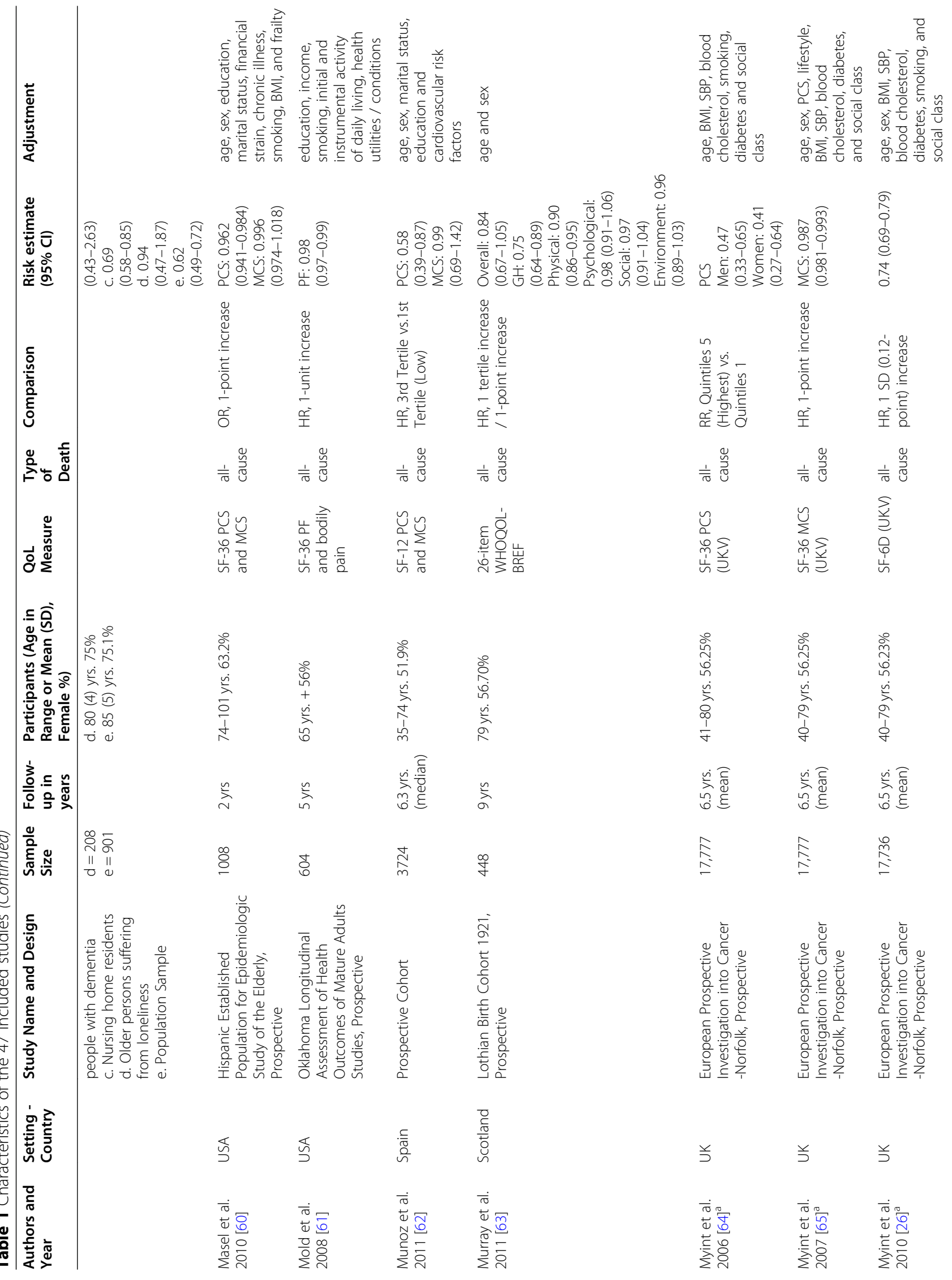




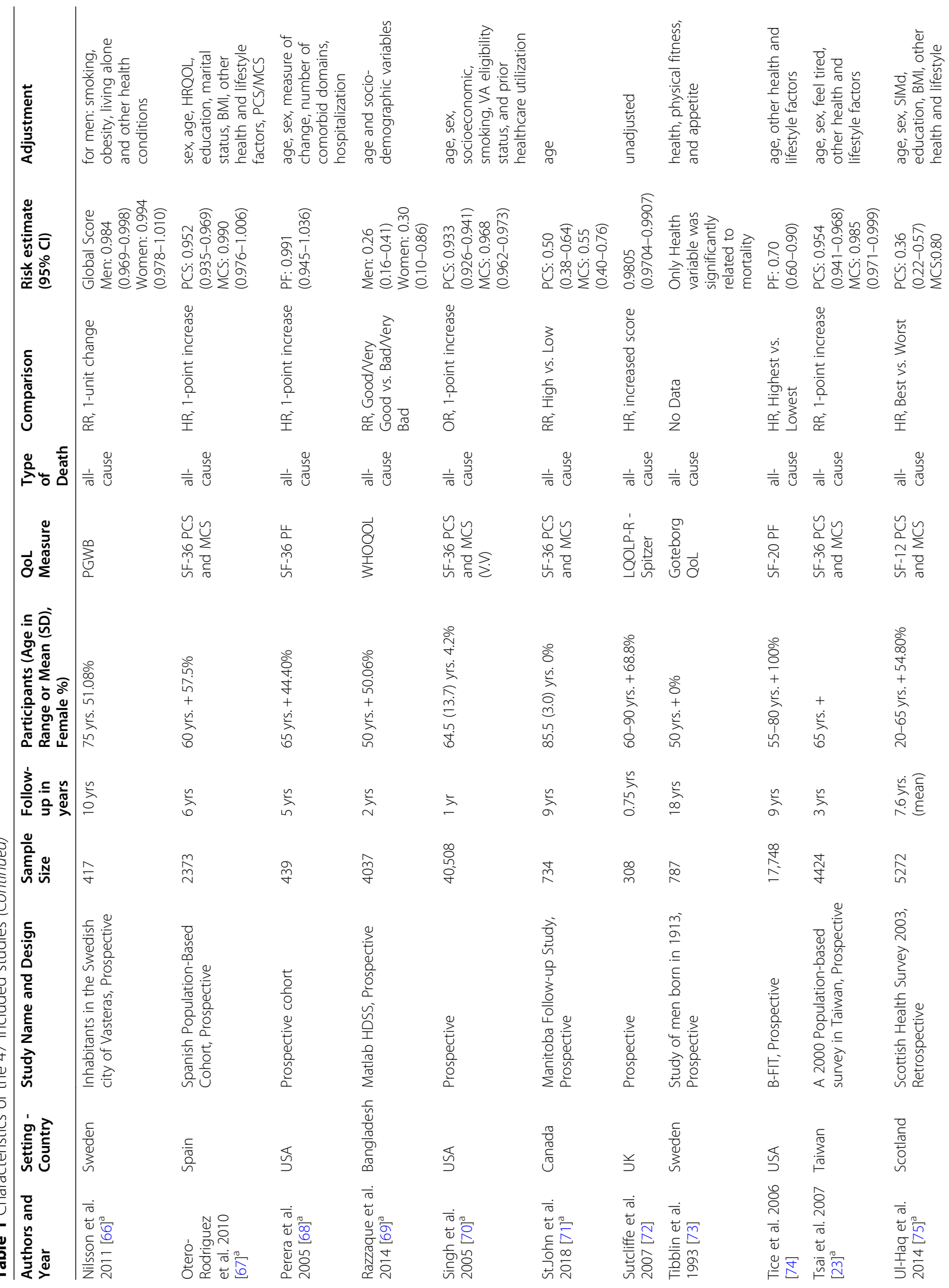




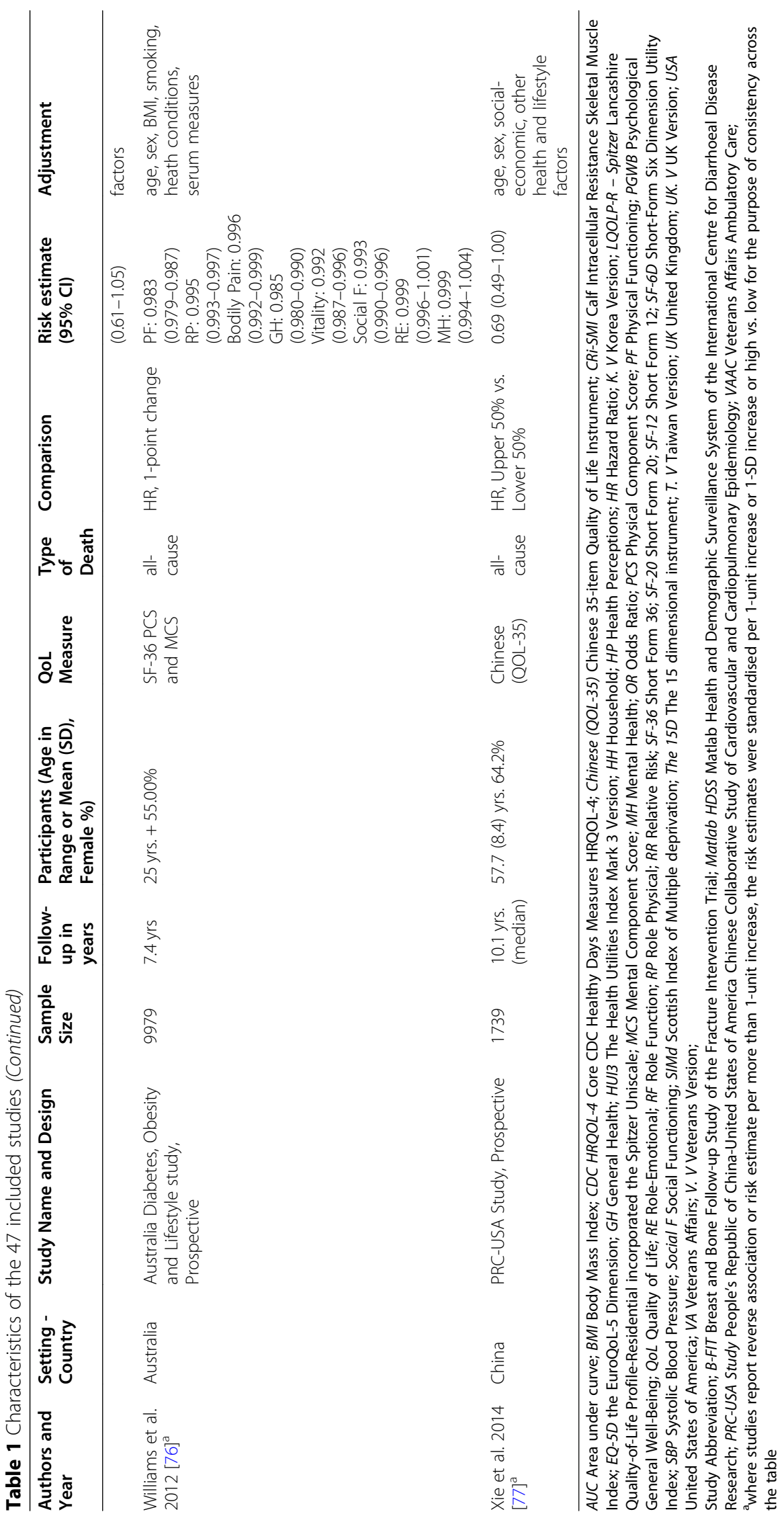


Table 2 Quality of life scale included in the systematic review

\begin{tabular}{|c|c|c|}
\hline \multicolumn{2}{|l|}{ QoL Scale } & \multirow{3}{*}{$\begin{array}{l}\text { Study } \\
\text { Study }[23,24,27,37,40-43,45-47, \\
49-52,56-62,64,65,67,68,70,71,74-76\end{array}$} \\
\hline Short Form Health Survey scales & SF-36, SF-20, SF-12, RAND-36 & \\
\hline & & \\
\hline World Health Organization questionnaires & WHOQOL, WHOQOL-BREF & Study $[25,54,63,69]$ \\
\hline $\begin{array}{l}\text { Centre for Diseases Control and Prevention Health Related } \\
\text { Quality of Life scale }\end{array}$ & CDC HRQOL & Study $[38,44]$ \\
\hline Six Dimensions Short Form Scale & SF-6D & Study $[26,53]$ \\
\hline Euro Quality of Life scale & EQ-5D & Study $[39,53]$ \\
\hline Health Utilities Index 3 & HUI3 & Study $[48,55]$ \\
\hline Psychological General Well-Being Index & PGWB & Study [66] \\
\hline 15-dimensional index & $15 \mathrm{D}$ & Study [29] \\
\hline Goteborg Quality of Life Instrument & Goteborg QoL & Study [73] \\
\hline $\begin{array}{l}\text { Lancashire Quality of Life Profile-Residential incorporated } \\
\text { the Spitzer Uniscale }\end{array}$ & $\begin{array}{l}\text { LQOLP-Residential incorporated the } \\
\text { Spitzer Uniscale }\end{array}$ & Study [72] \\
\hline Chinese 35-Item Quality of Life Instrument & Chinese QOL-35 & Study [77] \\
\hline
\end{tabular}

studies of Higueras-Fresnillo et al. and Otero-Rodriguez et al. were from the same Spanish cohort [52, 67], two published studies of Feeny et al. and Kaplan et al. were from the same Canadian cohort [48, 55]; and Myint et al. published three articles $[26,64,65]$ with different perspectives on the same population-based study. Additionally, Liira et al.'s study [29], included eight individual cohorts, however, only five of the cohorts met the inclusion criteria for this current systematic review, and thus are shown in Table 1.

\section{Risk of Bias assessment}

The methodological quality of included studies based on NOS ranged between five and nine stars. Among the included studies, seven were of high methodological quality, with nine stars. Across the ten studies with less than seven stars, they were scored most poorly on the items assessing how representative the cohort was in relation to the overall population being sampled and whether they adjusted for potential confounding factors in their analysis (See Supplementary Table S6-S7, Additional File 1).

\section{Qualitative synthesis}

Of the total 47 included studies, 43 (91.5\%) studies reported for at least one of the domains examined, that better QOL was associated with lower mortality risk (Table 1). Of 33 studies which assessed physical HRQoL (nine exclusively assessed physical HRQoL), 30 studies (91\%) reported better HRQoL was associated with lower mortality risk. Among the 23 studies which examined mental HRQoL (one exclusively assessed MCS), 13 studies (57\%) reported that higher mental HRQoL was associated with decreased mortality risk (Table 1 ). The five studies $[49,52$, $57,59,76]$ that measured HRQoL using SF-36 or SF-20 reported not only the physical functioning and mental health domains, but also general health perception, bodily pain, vitality, and social functioning. The findings were generally consistent in general health perception and social functioning; and it was reported that better level of general health perception and social functioning was associated with decreased mortality risk (Table 1).

The mortality risk estimates of the studies which were not included in the meta-analyses are shown in Tables 3, 4 and 5 . The 18 out of 20 studies which measured the PCS using the SF-36 or SF-12 or the physical functioning subscale using SF-36, RAND-36, or SF-20 reported these to be a predictor of mortality risk, with better physical health being associated with lower mortality risk (Table 3). Nine out of 16 studies which assessed the MCS or mental health subscale using SF-36 or SF-12, showed that better mental health was associated with lower mortality risk (Table 4). The 12 out of the 15 studies that measured the association between QoL and mortality risk, found that higher QoL scores were associated with lower mortality risk (Table 5).

\section{Meta-analyses}

Four studies including 53,642 participants [23, 24, 60, 70] measured QoL using the SF-36 and examined the association between the PCS and all-cause mortality and provided estimates from logistic regression analysis (OR or RR). With an average 1.8-year follow-up, one unit increase in the SF-36 PCS was associated with a 5\% decrease in all-cause mortality (pooled OR/RR $=0.950 ; 95 \%$ CI: 0.935 to 0.965 ; $P$-value $<0.001)$. There was substantial heterogeneity between studies $\left(\mathrm{I}^{2}=82.1 \%\right.$; $P$-value $=$ 0.001) (Fig. 2-a). 
Table 3 Physical component score / physical functioning as predictors of all-cause mortality

\begin{tabular}{|c|c|c|}
\hline Author (Year) & Comparison & Effect estimate $(95 \% \mathrm{Cl})$ \\
\hline \multicolumn{3}{|c|}{ SF - 36 Physical Component Score (continuous) } \\
\hline Chwastiak et al. 2010 [40] & HR, 1-unit increase & $0.97(0.96-0.98)$ \\
\hline DeSalvo et al. 2005 [43] & AUC & $0.73(0.71-0.75)$ \\
\hline Fan et al. 2006 [47] & AUC & $0.721(0.708-0.733)$ \\
\hline Otero-Rodriguez et al. 2010 [67] & HR, 1-unit increase & $0.952(0.935-0.969)$ \\
\hline \multicolumn{3}{|c|}{ SF-36 Physical Function Scale (continuous) } \\
\hline De Buyser et al. $2016^{\mathrm{a}, \mathrm{f}}[41]$ & HR, 1-unit increase & $1.01(0.99-1.02)$ \\
\hline Mold et al. $2008^{b}[61]$ & HR, 1-unit increase & $0.98(0.97-0.99)$ \\
\hline \multicolumn{3}{|c|}{ RAND-36 Physical Function Scale (continuous) } \\
\hline Bjorkman et al. 2019 [37] & HR, 1-unit increase & $0.988(0.979-0.997)$ \\
\hline \multicolumn{3}{|c|}{ SF - 36 Physical Component Score (categorised) } \\
\hline Forsyth et al. $2018^{f}[27]$ & HR, High vs. Low & $0.48(0.18-1.20)^{e}$ \\
\hline Han et al. 2009 [50] & HR, Tertile 3 High vs. Tertile 1Low & $0.35(0.19-0.64)$ \\
\hline Higueras-Fresnillo et al.2018 [52] & HR, Good vs. Poor & $0.74(0.65-0.85)$ \\
\hline Myint et al. $2006^{f}[64]$ & RR, Quintile 5 Highest vs. Quintile 1 Lowest & $\begin{array}{l}0.47(0.33-0.65) \text { Men } \\
0.41(0.27-0.64) \text { Women }\end{array}$ \\
\hline St. John et al. $2018^{f}[71]$ & RR, High vs. Low & $0.50(0.38-0.64)$ \\
\hline \multicolumn{3}{|c|}{ SF - 36 Physical Functioning (categorised) } \\
\hline Lee et al. $2012^{f}[58]$ & HR, Highest vs. Lowest & $0.29(0.19-0.45)$ \\
\hline \multicolumn{3}{|c|}{ SF - 36 Change in Physical Component Score (categorised) } \\
\hline \multirow[t]{2}{*}{ Kroenke et al. 2008 [56] } & RR, Severe Decline vs. No Change & $3.32(2.45-4.50)$ \\
\hline & RR, Improvement vs. No Change & $0.72(0.56-0.91)$ \\
\hline \multicolumn{3}{|c|}{ SF - 20 Physical Function Scale (continuous) } \\
\hline Franks et al. $2003^{f}[49]$ & HR, 1-point increase0.995 (0.992-0.997) & $0.995(0.992-0.997)$ \\
\hline \multicolumn{3}{|c|}{ SF - 20 Physical Function Scale (categorised) } \\
\hline Tice et al. 2006 [74] & HR, Highest vs. Lowest & $0.70(0.60-0.90)$ \\
\hline \multicolumn{3}{|c|}{ SF - 12 Physical Component Score (categorised) } \\
\hline Dorr et al. $2006^{f}[45]$ & OR, Highest Quartile vs. Lowest Quartile & 0.16 \\
\hline Haring et al. $2011^{f}[51]$ & HR, Highest Quartile vs. Lowest Quartile & $\begin{array}{l}0.56(0.42-0.75)^{c} \\
0.63(0.47-0.84)^{d}\end{array}$ \\
\hline Munoz et al. 2011 [62] & HR, 3rd Tertile vs. 1st Tertile & $0.58(0.39-0.87)$ \\
\hline Ul-Haq et al. 2014 [75] & HR, Best Quintile vs. Worst Quintile & $0.36(0.22-0.57)$ \\
\hline
\end{tabular}

${ }^{\mathrm{a} D e}$ Buyser et al. (2016) and De Buyser et al. (2013) were from the same study. De Buyser et al. (2013) was included in meta-analysis

b Lawler et al. (2013) and Mold et al. (2008) were from the same study. Lawler et al. (2013) was included in meta-analysis

cbehavioural factors adjusted

${ }^{\mathrm{d}}$ comorbidities adjusted

e $\mathrm{Cl}$ is $99 \% \mathrm{Cl}$

${ }^{f}$ where studies report reverse association or risk estimate per more than 1-unit increase, the risk estimates were standardised per 1-unit increase or 1-SD increase or high vs. low for the purpose of consistency across the table

AUC Area under curve

Six studies including 22,570 participants [42, 46, 57, 59, 68, 76] measured QoL using the SF-36 and investigated the association between the physical functioning and all-cause mortality using time-to-event survival analysis. With an average 8.7-year follow-up, one unit increase in the SF-36 PF was associated with a $1.3 \%$ decrease in time to death (pooled $\mathrm{HR}=0.987 ; 95 \% \mathrm{CI}$ : 0.982 to $0.992 ; P$-value $<0.001)$. There was substantial heterogeneity between studies $\left(\mathrm{I}^{2}=83.8 \% ; P\right.$-value < 0.001) (Fig. 2-b).

Four studies including 53,642 participants [23, 24, 60, 70] measured QoL using the SF-36 and examined the association between the MCS and all-cause mortality reported estimates on logistic regression analysis (OR or $\mathrm{RR})$. With an average 1.8-year follow-up, one unit increase in the SF-36 MCS was associated with a $2 \%$ 
Table 4 Mental component score / mental health as predictors of all-cause mortality

\begin{tabular}{|c|c|c|}
\hline Author (Year) & Comparison & Effect estimate $(95 \% \mathrm{Cl})$ \\
\hline \multicolumn{3}{|c|}{ SF - 36 Mental Component Score (continuous) } \\
\hline DeSalvo et al. 2005 [43] & AUC & $0.68(0.66-0.70)$ \\
\hline Fan et al. 2006 [47] & AUC & $0.689(0.675-0.702)$ \\
\hline Myint et al. 2007 [65] & HR, 1-unit increase & $0.987(0.981-0.993)$ \\
\hline Otero-Rodriguez et al. 2010 [67] & HR, 1-unit increase & $0.990(0.976-1.006)$ \\
\hline \multicolumn{3}{|l|}{ SF - 36 Mental Health (continuous) } \\
\hline Leigh et al. 2015 [59] & $H R$, 1-unit increase & $1.00(0.997-1.002)$ \\
\hline Williams et al. $2012^{\text {d }}[76]$ & HR, 1-point-change & $0.999(0.994-1.004)$ \\
\hline \multicolumn{3}{|c|}{ SF - 36 Mental Component Score (categorised) } \\
\hline Forsyth et al. 2018 [27] & HR, High vs. Low & $0.38(0.16-0.91)^{c}$ \\
\hline Han et al. 2009 [50] & HR, Tertile 3 High vs. Tertile 1Low & $0.39(0.22-0.70)$ \\
\hline Higueras-Fresnillo et al. 2018 ${ }^{\mathrm{d}}$ [52] & HR, Good vs. Poor & $0.85(0.74-0.98)$ \\
\hline St. John et al. $2018^{d}[71]$ & RR, High vs. Low & $0.55(0.40-0.76)$ \\
\hline \multicolumn{3}{|c|}{ SF - 36 Change in Mental Component Score (categorised) } \\
\hline Kroenke et al. 2008 [56] & $\begin{array}{l}\text { RR, Severe Decline vs. No Change } \\
\text { RR, Improvement vs. No Change }\end{array}$ & $\begin{array}{l}1.86(1.17-2.97) \\
0.77(0.63-0.95)\end{array}$ \\
\hline \multicolumn{3}{|c|}{ SF - 20 Physical Function Scale (continuous) } \\
\hline Franks et al. $2003^{d}[49]$ & HR, 1-point increase & $1.00(0.996-1.003)$ \\
\hline \multicolumn{3}{|c|}{ SF - 12 Mental Component Score (categorised) } \\
\hline Dorr et al. $2006^{d}[45]$ & OR, Highest Quartile vs. Lowest Quartile & 0.40 \\
\hline \multirow[t]{2}{*}{ Haring et al. $2011^{d}[51]$} & HR, Highest Quartile vs. Lowest Quartile & $0.94(0.73-1.22)^{a}$ \\
\hline & & $1.04(0.81-1.35)^{b}$ \\
\hline Munoz et al. 2011 [62] & HR, 3rd Teritle vs. 1st Tertile & $0.99(0.69-1.42)$ \\
\hline Ul-Haq et al. 2014 ${ }^{d}[75]$ & HR, Best Quintile vs. Worst Quintile & $0.80(0.61-1.05)$ \\
\hline
\end{tabular}

behavioural factors adjusted

${ }^{\mathrm{b}}$ comorbidities adjusted

c $99 \% \mathrm{Cl}$

${ }^{d}$ where studies report reverse association or risk estimate per more than 1-unit increase, the risk estimates were standardised per 1-unit increase or 1-SD increase or high vs. low for the purpose of consistency across the table

AUC Area under curve

decrease in all-cause mortality (pooled $\mathrm{OR} / \mathrm{RR}=0.980$; 95\% CI: 0.969 to $0.992 ; P$-value $=0.001$ ). There was substantial heterogeneity between studies $\left(\mathrm{I}^{2}=75.9 \%\right.$; $P$ value $=0.01)$ (Fig. 2-c).

Given the heterogeneity identified in the three metaanalyses described above, the influence of individual studies on the pooled risk estimate was assessed. The removal of no single study affected the association (Supplementary Table S8 - S10, Additional File 1).

Five Finnish individual cohorts of the Liira et al. study including 2377 [29] measured QoL using the 15D index and explored its association with all-cause mortality using time-to-event survival analysis. With an average 2year follow-up, one SD (0.14) increase in the 15D index was associated with a $36.7 \%$ decrease in all-cause mortality (pooled HR $=0.633 ; 95 \%$ CI: 0.514 to $0.780 ; P$-value < $0.001)$. There was moderate heterogeneity between studies $\left(\mathrm{I}^{2}=49.4 \%\right.$; $P$-value $\left.=0.10\right)($ Fig. 3$)$.
Visual inspection of the funnel plots which were used to assess for publication bias were presented in the Supplementary Figures S1-S4, Additional File 1. For three of the four meta-analyses, there was no strong evidence of publication bias, however for the meta-analysis of MCS, this test was statistically significant $(P=0.04)$.

\section{Discussion}

This systematic review is the first to investigate the association between QoL and mortality in communitydwelling individuals with or without health conditions rather than patients in a hospital or people living in assisted living. It summarizes the findings from 47 studies including approximately 1,200,000 individuals aged predominantly 65 years and older (age range 18-101 years), with 46 studies (98\%) conducted in high-income or upper-middle-income countries. Overall thirteen different instruments were used to assess the association 
Table 5 Other QoL measures rather than SF / RAND, as predictor of all-cause mortality

\begin{tabular}{|c|c|c|}
\hline Author (Year) & Comparison & Effect estimate $(95 \% \mathrm{Cl})$ \\
\hline \multicolumn{3}{|c|}{ 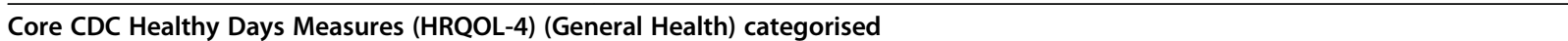 } \\
\hline Brown et al. 2015ª [38] & HR, Excellent vs. Poor & $0.24(0.21-0.27)$ \\
\hline Dominick et al. 2002 ${ }^{\mathrm{a}}$ [44] & RR, Excellent vs. Poor & $0.24(0.17-0.33)$ \\
\hline \multicolumn{3}{|l|}{ WHO QOL - BREF (Overall) } \\
\hline Kao et al. 2005 [54] & RR, 1-point change & $0.99(0.77-1.26)$ \\
\hline Murray et al. 2011 [63] & HR, 1-tertile increase & $0.84(0.67-1.05)$ \\
\hline \multicolumn{3}{|l|}{ WHO QOL (Categorised) } \\
\hline Gomez-Olive et al. 2014 [25] & HR, Highest vs. Lowest & 0.61 \\
\hline Razzaque et al. 2014ª [69] & RR, Good vs. Bad & $\begin{array}{l}0.26(0.16-0.41) \text { men } \\
0.30(0.10-0.86) \text { women }\end{array}$ \\
\hline \multicolumn{3}{|c|}{ Psychological General Well-being (PGWB) (Global Score) continuous } \\
\hline Nilsson et al. $2011^{\mathrm{a}}[66]$ & RR, 1-unit change & $\begin{array}{l}0.984(0.969-0.998) \text { men } \\
0.994(0.978-1.010) \text { women }\end{array}$ \\
\hline \multicolumn{3}{|c|}{ Lancashire Quality-of-life Profile-Residential (LQOLP-R) incorporated the Spitzer Uniscale } \\
\hline Sutcliffe et al. 2007 [72] & $H R$, increased score & $0.9805(0.9704-0.9907)$ \\
\hline \multicolumn{3}{|c|}{ Chinese 35-item Quality of Life (QOL-35) categorised } \\
\hline Xie et al. 2014 $[77]$ & HR, Upper 50\% vs. Lower 50\% & $0.69(0.49-1.00)$ \\
\hline \multicolumn{3}{|c|}{ The Health Utilities Index Mark 3 Version (HUI3) continuous } \\
\hline Feeny et al. 2012 [48] & HR, 1-level increase & $\begin{array}{l}\text { Hearing: } 0.18(0.06-0.57) \\
\text { Ambulation: } 0.10(0.04-0.23) \\
\text { Pain: } 0.53(0.29-0.96)\end{array}$ \\
\hline Kaplan et al. 2007 [55] & HR, 1-unit increase & Overall: $0.61(0.42-0.89)$ \\
\hline \multicolumn{3}{|c|}{ The EuroQoL-5 Dimension (EQ-5D) continuous } \\
\hline Cavrini et al. 2012 [39] & HR, 1-unit increase & $0.42(0.35-0.50)$ \\
\hline \multicolumn{3}{|c|}{ The EuroQoL-5 Dimension EQ-5D categorised } \\
\hline Jia et al. $2018^{\mathrm{a}}[53]$ & HR, 5th Quintile vs. 1st Quintile & $0.45(0.43-0.49)$ \\
\hline \multicolumn{3}{|c|}{ Short Form Six Dimension Utility Index (SF-6D) continuous } \\
\hline Myint et al. $2010^{\mathrm{a}}[26]$ & HR, 1SD 0.12-point increase & $0.74(0.69-0.79)$ \\
\hline \multicolumn{3}{|c|}{ Short Form Six Dimension Health Utility Measure (SF-6D) categorised } \\
\hline Jia et al. 2018 ${ }^{\mathrm{a}}[53]$ & HR, 5th Quintile vs. 1st Quintile & $0.77(0.71-0.80)$ \\
\hline \multicolumn{3}{|c|}{ Goteborg Quality of Life Assessment } \\
\hline Tibblin et al. 1993 [73] & \multicolumn{2}{|c|}{ Only Health variable was significantly related to mortality (No data available) } \\
\hline
\end{tabular}

${ }^{a}$ where studies report reverse association or risk estimate per more than 1-unit increase, the risk estimates were standardised per 1-unit increase or 1-SD increase or high vs. low for the purpose of consistency across the table

between QoL or more specifically HRQoL and mortality risk after 9 months to 18 years of follow-up, with the SF36 or its derivatives (RAND-36, SF-20, SF-6D) most commonly used. Overall, 43 (91.5\%) studies of the 47 included studies reported for at least one of the domains examined, that better QoL was associated lower mortality risk, which was also supported by the results of four meta-analyses (11 studies, $n=78,589$ ) of PCS, physical function and MCS domains of the SF-36, and 15D HRQoL.

Our findings are in line with a previous study that used pooled analysis [29] of eight heterogenous Finnish cohorts using the 15D HRQoL measure and included a wide range of both community-dwelling participants with or without morbidity, such as cardiovascular disease, dementia, and hospitalized patients with delirium. They also found that the 15D HRQoL measure was associated with two-year survival, with a slightly higher hazard ratio than that found in our study (HR per 1$\mathrm{SD}=0.44,95 \%$ CI 0.40 to 0.48) [29]. These differences may relate to their inclusion of patient groups in generally poorer health, while our systematic review focused on the community dwelling population. Moreover, our findings in the general non-patient population are also comparable with studies investigating people with specific diseases such as cancer 


\section{a SF-36 PCS}

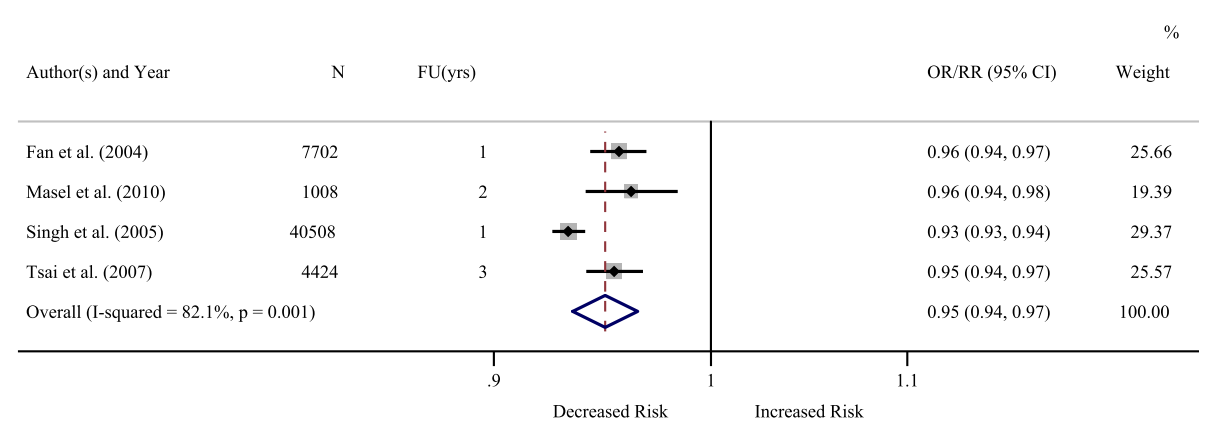

NOTE: Weights are from random-effects model

\section{b SF-36 Physical Functioning}

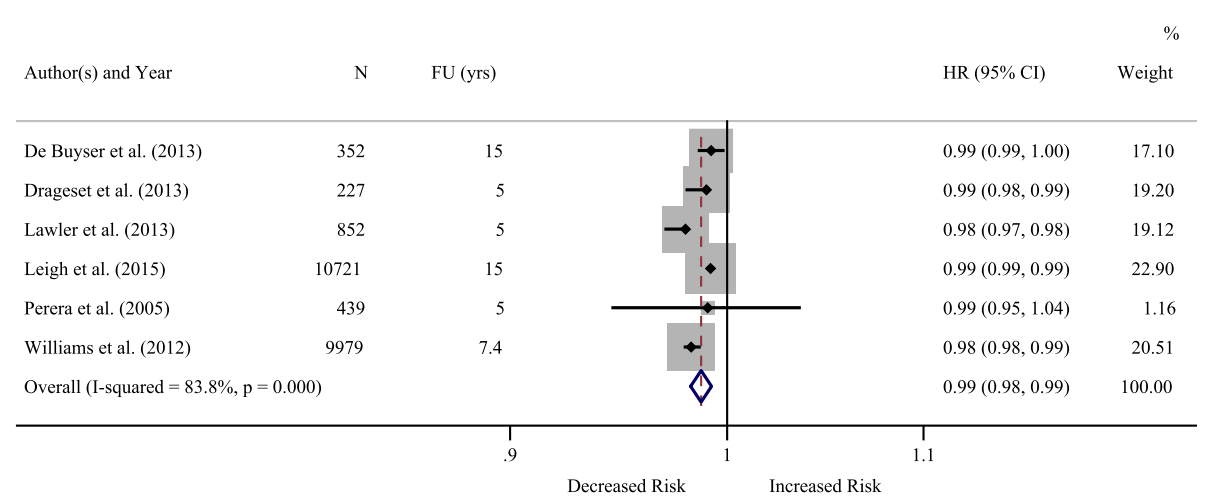

NOTE: Weights are from random-effects model

\section{c SF-36 MCS}

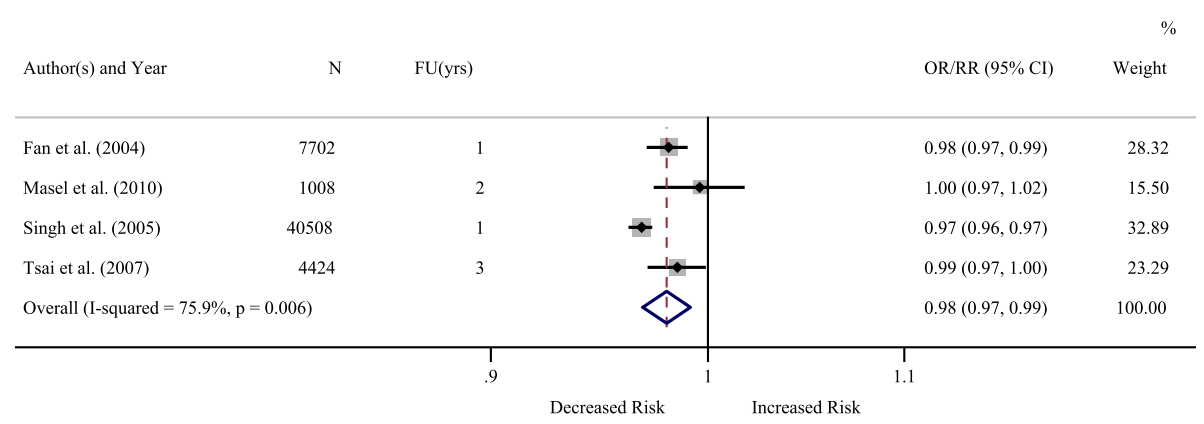

NOTE: Weights are from random-effects model

Fig. 2 Forest plot of all-cause mortality risk per one unit increase in a SF-36 PCS, b SF-36 Physical-Functioning, c SF-36 MCS. CI=Confidence interval; $F U$ (yrs) = follow-up in years; $N$ = sample size; $O R=$ odds ratio; $R R=$ relative risk; $H R=$ hazard ratio

and chronic kidney disease, which reported QoL to be a predictor of mortality risk [19-21].

The findings of the present study are also consistent with those of recent population-based systematic review which investigated on the association between QoL and multimorbidity [78]. In their recent study, Makovski et al. (2019) systematically reviewed the evidence on the relationship between QoL and multimorbidity. They observed a stronger relationship between the PCS of QoL and multimorbidity (overall decline in QoL per additional disease $=-4.37,95 \% \mathrm{CI}-7.13 \%$ to $-1.61 \%$ for WHOQoL-BREF physical domain and $-1.57,95 \% \mathrm{CI}-$ 


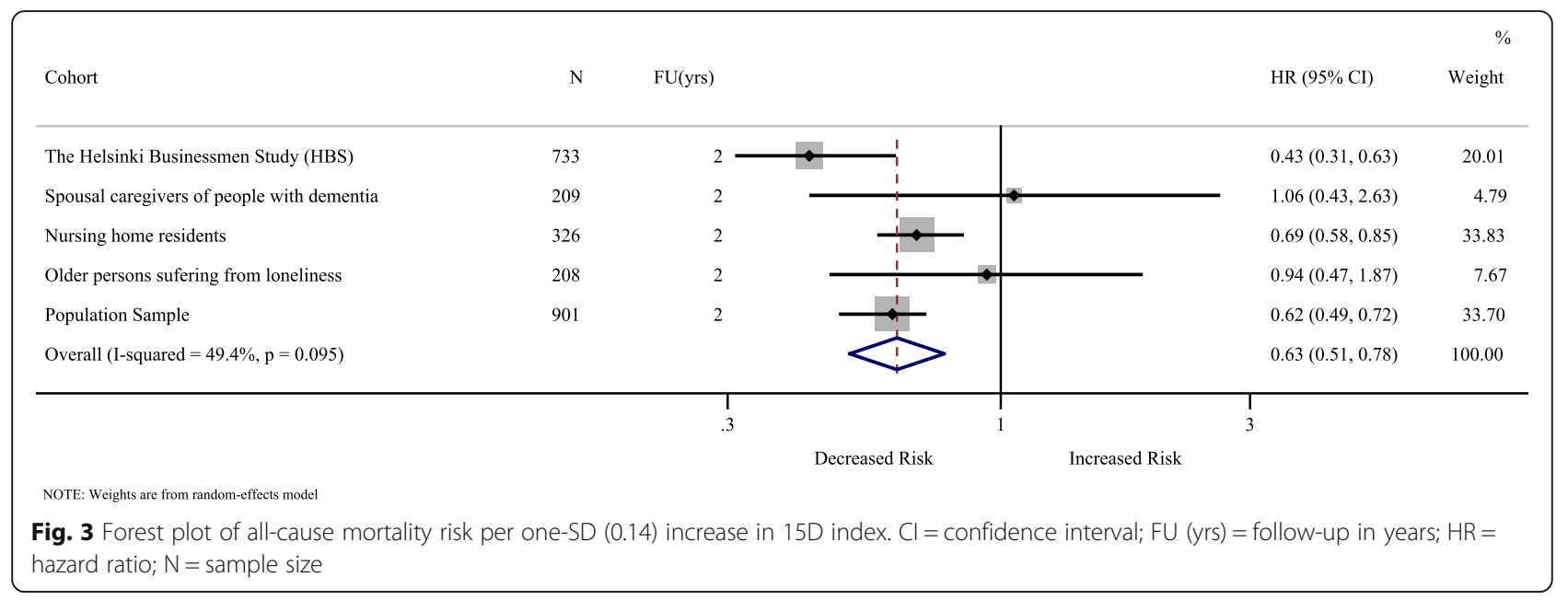

$2.70 \%$ to $-0.44 \%$ for WHOQoL-BREF mental domain) [78]. These findings also align with the results of the present study, where the meta-analysis indicated a stronger effect size for PCS compared to MCS using the SF-36 tool (pooled OR/RR $=0.950 ; 95 \% \mathrm{CI}: 0.935$ to 0.965 for PCS; and pooled OR/RR $=0.980 ; 95 \% \mathrm{CI}$ : 0.969 to 0.992 for MCS). Since physical health is generally recognised as a strong risk factor for comorbidity, hospitalisations and mortality [79-82], our findings add further support to the predictive capacity of physical HRQoL for mortality risk. Like other objective health measures such as body mass index, glycaemia, and blood pressure, these findings highlight the utility of assessing physical HRQoL in general clinical practice to help identify individuals at greatest risk of death [83].

Given the evidence regarding the longitudinal relationship between QoL and mortality risk, the utility of a QoL tool in general care may improve patient' health which in turn would decrease mortality. Furthermore, mental health issues such as depression or anxiety could also be identified through QoL measures and this would enable initiation of early interventions for mental health which in turn could improve long term QoL of individuals. Hence, the finding of this review can help to increase the efficacy of disease prevention strategies in older people through identifying individuals at higher risk for adverse health outcomes in general practice / primary health settings. Thus, the mortality risk prediction by QoL might not be very relevant to younger healthy populations although QoL generic measures were designed to be used across a wide range of populations [84]. There is a need for further studies however, in particular to better understand the influence of gender on these associations, and whether differences could be observed for males and females. Understanding these specific relationships could help identify which particular groups are most at risk and enable specific targeting of interventions to these individuals.

\section{Strengths of the review}

Strengths of this systematic review are that it was performed in a rigorous manner, adhering to strict systematic review guidelines. The protocol was registered with the International prospective register of systematic reviews (PROSPERO), and the review was undertaken in accordance with the preferred reporting items for systematic reviews and meta-analyses (PRISMA) statement. A reproducible and rigorous search strategy using three electronic databases was used, which helped ensure that all relevant articles were included. The literature screening was independently performed by two reviewers, who were also involved in the process of data extraction and methodological quality assessment of the included studies in accordance with NOS. Based on the NOS, all studies received greater than or equal to five out of nine stars, which indicates that there was generally a low risk of bias. Similarly, most studies provided risk estimates that controlled for important factors including current health and socio-economic status. Since our review criteria were not limited to articles with the commonly used QoL (or HRQoL) tools such as the SF-36, this has increased the generalisability of the findings. Therefore, this review has a broad and comprehensive perspective, with results that are rigorous and can be reproduced.

\section{Limitations of the review}

Among included articles, large heterogeneity was observed in terms of country-of-origin, participant characteristics, and evaluation of QoL. The majority of the included articles were conducted in English speaking counties, and restriction to English language articles as part of our inclusion criteria, may impact the generalisability of these findings. Since the different QoL 
standard tools examine different aspects [33, 85] and are not directly comparable, this made comparison of included studies in data synthesis difficult. There were also some differences in the way the data analysis was performed and the results were presented, reporting OR versus $H R$ for example. In addition, some articles reported the risk estimates by comparing categorical QoL groups while others provided the risk estimates per 1 or more units change in the continuous scale. Hence, the different nature of each QoL scale and inconsistency in risk comparison precluded us from including some articles in the meta-analyses. As such, only 11 studies were included across the four meta-analyses of this systematic review, and the meta-analyses still showed substantial heterogeneity. Therefore, caution should be taken with the interpretation of the overall effect estimates. Moreover, since the numbers of studies included in each meta-analysis were fewer than 10 studies, the results of funnel plots or Egger's test should also be interpreted with caution. Of particular interest here, it has commonly been reported that gender differences exist in QoL and women of all age groups have lower QoL than their male counterparts [86-90]. However, in this review, it was not possible to perform statistical pooling by gender and age groups due to the different reporting strategies of the reviewed studies. Finally, it is important to consider that although studies of mortality are not directly affected by reverse causation, individuals with severely declining health prior to death, would likely report a decreased HRQoL. An ideal study design would involve excluding individuals who died in the first year of the study, or at least, to run sensitivity analysis to ensure these early deaths were not driving the results. Most of the studies included in this review, did not undertake such analyses. Furthermore, around $10 \%$ of the included studies have very short follow-up periods of less than 2 years.

\section{Conclusion}

This is the first systematic review and meta-analysis that has determined whether QoL is associated with mortality in the general non-patient population. In summary, the findings provide evidence that better QoL or HRQoL measured by different tools were associated with lower mortality risk in the general population. Therefore, our findings could be applied more generally to QoL or HRQoL assessed using different instruments. Our unique and first review indicates that QoL measures can be considered as potential screening tools beyond the existing traditional clinical assessment of mortality risk. Additionally, our result also encourages clinicians to incorporate QoL measure into routine data collection of health system which in turn could enable initiation of early primary health care for people at high risk of premature death. Furthermore, this study also adds further support to the predictive capacity of physical HRQoL for mortality risk. Additional research is needed to determine whether these associations differ across gender, and other populations in low- and lower-middle-income countries, who have suffered of a double burden of infectious and chronic diseases, with having difficulties for accessing quality health services. Ultimately these findings suggest the utility of QoL measures to help identify populations at greatest risk of mortality and who might benefit most from routine screening in general practice and possible interventions.

\section{Supplementary information}

Supplementary information accompanies this paper at https://doi.org/10 1186/s12889-020-09639-9.

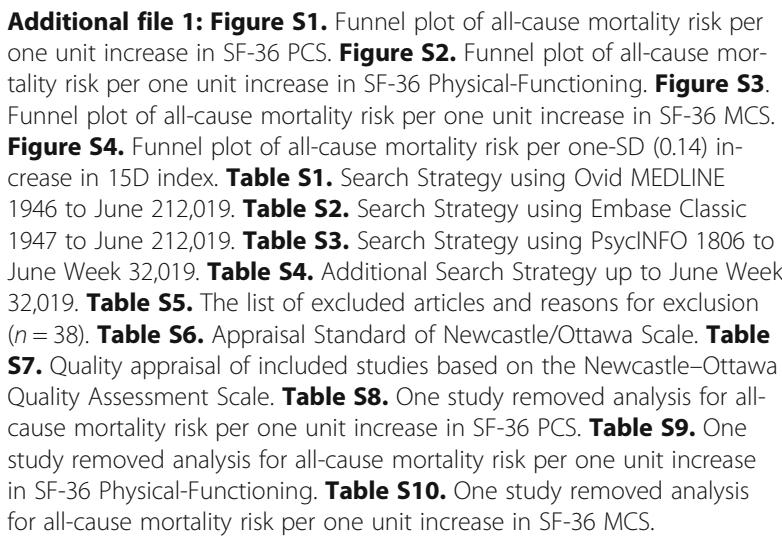
one unit increase in SF-36 PCS. Figure S2. Funnel plot of all-cause mortality risk per one unit increase in SF-36 Physical-Functioning. Figure S3. Funnel plot of all-cause mortality risk per one unit increase in SF-36 MCS. Figure S4. Funnel plot of all-cause mortality risk per one-SD (0.14) increase in 15D index. Table S1. Search Strategy using Ovid MEDLINE 1946 to June 212,019. Table S2. Search Strategy using Embase Classic 1947 to June 212,019. Table S3. Search Strategy using PsycINFO 1806 to June Week 32,019. Table S4. Additional Search Strategy up to June Week 32,019 . Table S5. The list of excluded articles and reasons for exclusion $(n=38)$. Table S6. Appraisal Standard of Newcastle/Ottawa Scale. Table S7. Quality appraisal of included studies based on the Newcastle-Ottawa Quality Assessment Scale. Table S8. One study removed analysis for allcause mortality risk per one unit increase in SF-36 PCS. Table S9. One study removed analysis for all-cause mortality risk per one unit increase in SF-36 Physical-Functioning. Table S10. One study removed analysis for all-cause mortality risk per one unit increase in SF-36 MCS.

\section{Abbreviations}

15D: 15-dimentional; Cl: Confidence intervals; EQ-5D: Euroqol-5 dimension; $\mathrm{HR}$ : Hazard ratio; HRQOL : Health-related quality of life; HUI3 : Health utilities index 3; MCS : Mental component score; NOS : NEWCASTLE-Ottawa quality assessment scale; OR : Odds ratio; PCS : Physical component score; PRISMA : Preferred reporting items for systematic reviews and meta-analyses; PROMs : Patient reported outcome measures; PROSPERO : International prospective register of systematic reviews; QoL : Quality of life; RR : Relative risk; SD : Standard deviation; SF-12 : 12-items short form; SF-20 : 20-item short form; SF-36 : 36-item short form; SF-6D : Six-dimension utility index

\section{Acknowledgements}

We would like to thank Lorena Romero, the Senior Medical Librarian, Alfred Health, and Cassandra Freeman, the Subject Librarian, Faculty of Medicine, Nursing and Health Sciences, Monash University Library for technical support involved in developing the search strategy.

\section{Authors' contributions}

RFP conceived the study. JR and AZZP designed the study. AZZP undertook the literature searches, screened the articles, extracted the data, performed quality assessment and data analysis. HC was the independent assessor, also completing all data screening, extraction and quality assessment. AZZP and JR interpreted the data, with input from DAGC, DG, and NPS. AZZP wrote the initial manuscript draft. All authors provided critical comments and approved the final version. 


\section{Funding}

This work was supported by Monash International Tuition Scholarship and Monash Graduate Scholarship. AZZP is supported by Monash International Tuition Scholarship (Medicine, Nursing, and Health Sciences) and Monash Graduate Scholarship (30072360). JR is supported by a National Health and Medical Research Council Dementia Research Leader Fellowship (APP1135727). None of the funders were involved in the design of the study, in the collection, analysis, and interpretation of data and in the writing of the manuscript.

\section{Availability of data and materials}

All data generated or analysed during this study are included in this published article (and its supplementary information files).

\section{Ethics approval and consent to participate}

This is a systematic review and meta-analysis of publicly available studies. No ethical approval was required.

\section{Consent for publication}

Not applicable.

\section{Competing interests}

The authors declare no conflicts of interest.

\section{Author details}

${ }^{1}$ School of Public Health and Preventive Medicine, Monash University, 99 Commercial Road, Melbourne, VIC 3004, Australia. '2Department of Epidemiology, Erasmus Medical Centre, 3015 GD Rotterdam, The Netherlands. ${ }^{3}$ Usher Institute, University of Edinburgh, Teviot Place, Edinburgh EH8 9AG, UK. ${ }^{4}$ Discipline of General Practice, Adelaide Medical School, The University of Adelaide, Adelaide, SA 5005, Australia. ${ }^{5}$ Adelaide Rural Clinical School, The University of Adelaide, Adelaide, SA 5005, Australia. ${ }^{6}$ PSNREC, Univ Montpellier, INSERM, 34000 Montpellier, France.

Received: 22 January 2020 Accepted: 1 October 2020 Published online: 06 November 2020

\section{References}

1. Kuyken W, Orley J, Power M, Herrman H, Schofield H, Murphy B, et al. The World Health Organization quality of life assessment (WHOQOL): position paper from the World Health Organization. Soc Sci Med. 1995;41(10):1403-9.

2. Ware JE. The status of health assessment 1994. Annu Rev Public Health. 1995;16(1):327-54.

3. Elkinton JR. Medicine and the quality of life. Ann Intern Med. 1966;64(3):711.

4. Spitzer WO. State of science 1986: quality of life and functional status as target variables for research. J Chronic Dis. 1987;40(6):465-71.

5. World Health Organization. World report on ageing and health. Geneva: World Health Organization 2015 [Available from: http://www.who.int/ ageing/publications/world-report-2015/en/.

6. Brown GC. Living too long. EMBO reports. 2015. Report No.: 1469-221X Contract No.: 2.

7. World Health Organization. Global Health Observatory (GHO) data 2019 [cited 2019 August 27]. Available from: https://www.who.int/gho/mortality_ burden_disease/life_tables/situation_trends_text/en/.

8. Centers for Disease Control and Prevention. Health-Related Quality of Life (HRQOL) Concept 2018 [cited 2019 August 27]. Available from: https://www. cdc.gov/hrqol/concept.htm.

9. Salomon JA, Wang H, Freeman MK, Vos T, Flaxman AD, Lopez AD, et al. Healthy life expectancy for 187 countries, 1990-2010: a systematic analysis for the global burden disease study 2010. Lancet. 2012;380(9859):2144-62.

10. Centers for Disease Control and Prevention. Measuring Healthy Days: Population Assessment of Health-Related Quality of Life. Atlanta, Georgia: CDC; 2000.

11. Centers for Disease Control and Prevention. Healthy People 20202019 [cited 2019 August 14]. Available from: https://www.cdc.gov/nchs/healthy people/hp2020.htm

12. World Health Organization. International Classification of Functioning, disability, and Health: Children and Youth Version: ICF-CY. Geneva: World Health Organization; 2007.
13. Sintonen $\mathrm{H}$. The $15 \mathrm{D}$ measure of health-related quality of life: reliability, validity and sensitivity of its health state descriptive system. Working Paper 41. Melbourne: National Centre for Health Program Evaluation; 1994.

14. Gross RC, Limwattananon LC, Matthees LB, Zehrer LJ, Savik LK. Impact of transplantation on quality of life in patients with diabetes and renal dysfunction. Transplantation. 2000;70(12):1736-46.

15. Moinpour CM, Savage MJ, Troxel A, Lovato LC, Eisenberger M, Veith RW, et al. Quality of life in advanced prostate Cancer: results of a randomized therapeutic trial. J Urol. 1999;161(4):1394-5.

16. Rodríguez-Artalejo F, Guallar-Castillón P, Pascual CR, Otero CM, Montes AO, García AN, et al. Health-related quality of life as a predictor of hospital readmission and death among patients with heart failure. Arch Intern Med. 2005;165(11):1274-9.

17. Rumsfeld JS, Mawhinney S, McCarthy M, Shroyer AL, Villanueva CB, O'Brien $M$, et al. Health-related quality of life as a predictor of mortality following coronary artery bypass graft surgery. Participants of the Department of Veterans Affairs Cooperative Study Group on Processes, Structures, and Outcomes of Care in Cardiac Surgery. JAMA. 1999;281(14):1298.

18. Domingo-Salvany A, Lamarca R, Ferrer M, Garcia-Aymerich J, Alonso J, Félez $M$, et al. Health-related quality of life and mortality in male patients with chronic obstructive pulmonary disease. Am J Respir Crit Care Med. 2002; 166(5):680.

19. Mehanna HM, Morton RP. Does quality of life predict long-term survival in patients with head and neck Cancer? Arch Otolaryngology-Head \& Neck Surgery. 2006;132(1):27-31.

20. Maisey NR, Norman A, Watson M, Allen MJ, Hill ME, Cunningham D. Baseline quality of life predicts survival in patients with advanced colorectal cancer Eur J Cancer. 2002;38(10):1351-7.

21. Tsai YC, Hung CC, Hwang SJ, Wang SL, Hsiao SM, Lin MY, et al. Quality of life predicts risks of end-stage renal disease and mortality in patients with chronic kidney disease. Nephrology Dialysis Transplantation. 2010;25(5): 1621-6.

22. Rumsfeld SJ, Mawhinney AWS, McCarthy BM, Shroyer EL, Villanueva GC, O'brien LM, et al. Health-Related Quality of Life As a Predictor of Mortality Following Coronary Artery Bypass Graft Surgery. Survey of Anesthesiology. 2000:44(6):326.

23. Tsai SY, Chi LY, Lee CH, Chou P. Health-related quality of life as a predictor of mortality among community-dwelling older persons. Eur J Epidemiol. 2007;22(1):19-26.

24. Fan VS, Au DH, McDonell MB, Fihn SD. Intraindividual change in SF-36 in ambulatory clinic primary care patients predicted mortality and hospitalizations. J Clin Epidemiol. 2004;57(3):277-83.

25. Gomez-Olive FX, Thorogood M, Bocquier P, Mee P, Kahn K, Berkman L, et al. Social conditions and disability related to the mortality of older people in rural South Africa. Int J Epidemiol. 2014:43(5):1531-41.

26. Myint PK, Smith RD, Luben RN, Surtees PG, Wainwright NWJ, Wareham NJ et al. The short-form six-dimension utility index predicted mortality in the European prospective investigation into Cancer-Norfolk prospective population-based study. J Clin Epidemiol. 2010;63(2):192-8.

27. Forsyth SJ, Carroll M, Lennox N, Kinner SA. Incidence and risk factors for mortality after release from prison in Australia: a prospective cohort study. Addiction. 2018;113(5):937-45.

28. Linde L, Sørensen J, Ostergaard M, Hørslev-Petersen K, Hetland ML. Healthrelated quality of life: validity, reliability, and responsiveness of SF-36, 15D, EQ-5D corrected RAQoL, and HAQ in patients with rheumatoid arthritis. J Rheumatol. 2008;35(8):1528.

29. Liira $H$, Mavaddat $N$, Eineluoto $M$, Kautiainen $H$, Strandberg $T$, Suominen $M$, et al. Health-related quality of life as a predictor of mortality in heterogeneous samples of older adults. European Geriatric Medicine. 2018; 9(2):227-34

30. Liberati A, Altman DG, Tetzlaff J, Mulrow C, Gøtzsche PC, loannidis JPA, et al. The PRISMA statement for reporting systematic reviews and meta-analyses of studies that evaluate healthcare interventions: explanation and elaboration. BMJ. 2009;339(jul21):1.

31. Booth A, Clarke M, Ghersi D, Moher D, Petticrew M, Stewart L. An international registry of systematic-review protocols. Lancet. 2011;377(9760):108-9.

32. Phyo. AZZ, Craig. H, Gonzalez-Chica. DA, Stocks. N, Freak-Poli. R, Ryan. J, et al. Quality of life as a predictor of mortality: a systematic review and meta-analysis PROSPERO 2019 CRD42019139994 [cited 2019 September 8]. Available from: https://www.crd.york.ac.uk/prospero/display_record.php? ID= CRD42019139994. 
33. Karimi M, Brazier J. Health, health-related quality of life, and quality of life: what is the difference? PharmacoEconomics. 2016;34(7):645-9.

34. Covidence systematic review software, Veritas Health Innovation, Melbourne, Australia [cited 2019 June 10]. Available from: www.covidence.org.

35. The Ottawa Hospital Research Institute. The Newcastle-Ottawa Scale (NOS) for assessing the quality if nonrandomized studies in meta-analyses [cited 2019 July 10]. Available from: http://www.ohri.ca/programs/clinical_ epidemiology/oxford.asp.

36. Higgins JPT, Green S. Cochrane Handbook for Systematic Reviews of Interventions Version 5.1.0. The Cochrane Collaboration 2011 [cited 2019 August 8]. Available from: http://training.cochrane.org/handbook.

37. Bjorkman MP, Pitkala KH, Jyvakorpi S, Strandberg TE, Tilvis RS. Bioimpedance analysis and physical functioning as mortality indicators among older sarcopenic people. Exp Gerontol. 2019;122:42-6.

38. Brown D, Thompson W, Zack M, Arnold S, Barile J. Associations between health-related quality of life and mortality in older adults. Prev Sci. 2015; 16(1):21-30.

39. Cavrini G, Broccoli S, Puccini A, Zoli M. EQ-5D as a predictor of mortality and hospitalization in elderly people. Qual Life Res. 2012;21(2):269-80.

40. Chwastiak LA, Rosenheck RA, Desai R, Kazis LE. Association of psychiatric illness and all-cause mortality in the national Department of Veterans Affairs health care system. Psychosom Med. 2010;72(8):817-22.

41. De Buyser S, Petrovic M, Taes $Y$, Toye K, Kaufman JM, Goemaere $S$, et al. Three year functional changes and long-term mortality hazard in community-dwelling older men. Eur J Int Med. 2016;35:66-72.

42. De Buyser SL, Petrovic M, Taes YE, Toye KRC, Kaufman JM, Goemaere S. Physical function measurements predict mortality in ambulatory older men. Eur J Clin Investig. 2013;43(4):379-86.

43. DeSalvo KB, Fan VS, McDonell MB, Finn SD. Predicting mortality and healthcare utilization with a single question. Health Serv Res. 2005;40(4):1234-46.

44. Dominick KL, Ahern FM, Gold CH, Heller DA. Relationship of health-related quality of life to health care utilization and mortality among older adults. Aging Clin Exp Res. 2002;14(6):499-508.

45. Dorr DA, Jones SS, Burns L, Donnelly SM, Brunker CP, Wilcox A, et al. Use of health-related, quality-of-life metrics to predict mortality and hospitalizations in community-dwelling seniors. J Am Geriatr Soc. 2006;54(4):667-73.

46. Drageset J, Eide GE, Ranhoff AH. Mortality in nursing home residents without cognitive impairment and its relation to self-reported healthrelated quality of life, sociodemographic factors, illness variables and cancer diagnosis: a 5-year follow-up study. Qual Life Res. 2013;22(2): 317-25.

47. Fan VS, Maciejewski ML, Liu CF, McDonell MB, Fihn SD. Comparison of risk adjustment measures based on self-report, administrative data, and pharmacy records to predict clinical outcomes. Health Serv Outcomes Res Methodology. 2006;6(1-2):21-36.

48. Feeny D, Huguet N, McFarland BH, Kaplan MS, Orpana H, Eckstrom E. Hearing, mobility, and pain predict mortality: a longitudinal populationbased study. J Clin Epidemiol. 2012;65(7):764-77.

49. Franks P, Gold MR, Fiscella K. Sociodemographics, self-rated health, and mortality in the US. Soc Sci Med. 2003;56(12):2505-14.

50. Han SS, Kim KW, Na KY, Chae DW, Kim YS, Kim S, et al. Quality of life and mortality from a nephrologist's view: a prospective observational study. BMC Nephrol. 2009;10(1):39.

51. Haring R, Feng Y-S, Moock J, Völzke H, Dörr M, Nauck M, et al. Selfperceived quality of life predicts mortality risk better than a multi-biomarker panel, but the combination of both does best. BMC Med Res Methodol. 2011;11(1):103.

52. Higueras-Fresnillo S, Cabanas-Sanchez V, Garcia-Esquinas E, RodriguezArtalejo F, Martinez-Gomez D. Physical activity attenuates the impact of poor physical, mental, and social health on total and cardiovascular mortality in older adults: a population-based prospective cohort study. Qual Life Res. 2018;27(12):3293-302.

53. Jia H, Lubetkin El, Demichele K, Stark DS, Zack MM, Thompson WW. Comparing the performance of 2 health utility measures in the Medicare health outcome survey (HOS). Med Decis Mak. 2018;38(8):983-93.

54. Kao S, Lai K-L, Lin H-C, Lee H-S, Wen H-C. WHOQOL-BREF as predictors of mortality: a two-year follow-up study at veteran homes. Qual Life Res. 2005; 14(6):1443-54.

55. Kaplan MS, Berthelot JM, Feeny D, McFarland BH, Khan S, Orpana H. The predictive validity of health-related quality of life measures: mortality in a longitudinal population-based study. Qual Life Res. 2007;16(9):1539-46.
56. Kroenke CH, Kubzansky LD, Adler N, Kawachi I. Prospective change in health-related quality of life and subsequent mortality among middle-aged and older women. Am J Public Health. 2008;98(11):2085-91.

57. Lawler FH, Mold JW, McCarthy LH. Do older people benefit from having a confidant? An Oklahoma physicians resource/research network (OKPRN) study. J Am Board Family Med. 2013;26(1):9-15.

58. Lee MS, Chen RCY, Chang YH, Huang YC, Wahlqvist ML. Physical function mitigates the adverse effects of being thin on mortality in a free-living older Taiwanese cohort. J Nutr Health Aging. 2012;16(9):776-83.

59. Leigh L, Hudson IL, Byles JE. Sleeping difficulty, disease and mortality in older women: a latent class analysis and distal survival analysis. J Sleep Res. 2015;24(6):648-57.

60. Masel MC, Ostir GV, Ottenbacher KJ. Frailty, mortality, and health-related quality of life in older Mexican Americans. J Am Geriatr Soc. 2010;58(11): 2149-53.

61. Mold JW, Lawler F, Roberts M. The health consequences of peripheral neurological deficits in an elderly cohort: an Oklahoma physicians resource/ research network study. J Am Geriatr Soc. 2008;56(7):1259-64.

62. Munoz MA, Subirana I, Elosua R, Covas MI, Baena-Diez JM, Ramos R, et al. Utility of a short quality of life questionnaire to predict cardiovascular events. Int J Cardiol. 2011;151(3):392-4.

63. Murray C, Brett CE, Starr JM, Deary IJ. Which aspects of subjectively reported quality of life are important in predicting mortality beyond known risk factors? The Lothian birth cohort 1921 study. Qual Life Res. 2011;20(1):81-90.

64. Myint PK, Luben RN, Surtees PG, Wainwright NWJ, Welch AA, Bingham SA, et al. Relation between self-reported physical functional health and chronic disease mortality in men and women in the European prospective investigation into Cancer (EPIC-Norfolk): a prospective population study. Ann Epidemiol. 2006;16(6):492-500.

65. Myint PK, Luben RN, Surtees PG, Wainwright NWJ, Welch AA, Bingham SA, et al. Self-reported mental health-related quality of life and mortality in men and women in the European prospective investigation into Cancer (EPICNorfolk): a prospective population study. Psychosom Med. 2007;69(5):410-4

66. Nilsson G, Ohrvik J, Lonnberg I, Hedberg P. Low psychological general wellbeing (PGWB) is associated with deteriorated 10-year survival in men but not in women among the elderly. Arch Gerontol Geriatr. 2011;52(2):167-71.

67. Otero-Rodriguez A, Leon-Munoz LM, Balboa-Castillo T, Banegas JR, Rodriguez-Artalejo F, Guallar-Castillon P. Change in health-related quality of life as a predictor of mortality in the older adults. Qual Life Res. 2010;19(1):15-23.

68. Perera S, Studenski S, Chandler JM, Guralnik JM. Magnitude and patterns of decline in health and function in 1 year affect subsequent 5-year survival. J Gerontol A Biol Sci Med Sci. 2005;60(7):894-900.

69. Razzaque A, Mustafa AHMG, Streatfield PK. Do self-reported health indicators predict mortality? Evidence from Matlab, Bangladesh. J Biosocial Sci. 2014;46(5):621-34.

70. Singh JA, Borowsky SJ, Nugent S, Murdoch M, Zhao Y, Nelson DB, et al. Health-related quality of life, functional impairment, and healthcare utilization by veterans: veterans' quality of life study. J Am Geriatr Soc. 2005; 53(1):108-13.

71. St. John PD, Jiang D, Tate RB. Quality of life trajectories predict mortality in older men: the Manitoba follow-up study. J Aging Health. 2018;30(2):247-61.

72. Sutcliffe C, Burns A, Challis D, Mozley CG, Cordingley L, Bagley H, et al. Depressed mood, cognitive impairment, and survival in older people admitted to care homes in England. Am J Geriatr Psychiatry. 2007;15(8): 708-15.

73. Tibblin G, Svärdsudd K, Welin L, Erikson H, Larsson B. Quality of life as an outcome variable and a risk factor for total mortality and cardiovascular disease: a study of men born in 1913. J Hypertension Supplement. 1993; 11(4):S81.

74. Tice JA, Kanaya A, Hue T, Rubin S, Buist DSM, Lacroix A, et al. Risk factors for mortality in middle-aged women. Arch Intern Med. 2006;166(22):2469-77.

75. Ul-Haq Z, Mackay DF, Pell JP. Association between physical and mental health-related quality of life and adverse outcomes; a retrospective cohort study of 5,272 Scottish adults. BMC Public Health. 2014;14:1197.

76. Williams ED, Rawal L, Oldenburg BF, Renwick C, Shaw JE, Tapp RJ. Risk of cardiovascular and all-cause mortality: impact of impaired health-related functioning and diabetes - the Australian diabetes, obesity and lifestyle (AusDiab) study. Diabetes Care. 2012;35(5):1067-73. 
77. Xie G, Laskowitz DT, Turner EL, Egger JR, Shi P, Ren F, et al. Baseline healthrelated quality of life and 10-year all-cause mortality among 1739 Chinese adults. PLoS One. 2014;9(7):e101527.

78. Makovski TT, Schmitz S, Zeegers MP, Stranges S, van Den Akker M Multimorbidity and quality of life: systematic literature review and metaanalysis. Ageing Res Rev. 2019;53:100903.

79. Macnee W, Rabinovich RA, Choudhury G. Ageing and the border between health and disease. Eur Respir J. 2014;44(5):1332.

80. Donat Tuna H, Ozcan Edeer A, Malkoc M, Aksakoglu G. Effect of age and physical activity level on functional fitness in older adults.(Report). European Review of Aging and Physical Activity. 2009;6(2):99.

81. Goldspink DF. Ageing and activity: their effects on the functional reserve capacities of the heart and vascular smooth and skeletal muscles. Ergonomics. 2005;48(11-14):1334.

82. Brach JS, Fitzgerald S, Newman AB, Kelsey S, Kuller L, Vanswearingen $\mathrm{JM}$, et al. Physical activity and functional status in community-dwelling older women: a 14-year prospective study. Arch Intern Med. 2003; 163(21):2565-71.

83. Ju S-Y, Lee J-Y, Kim D-H. Association of metabolic syndrome and its components with all-cause and cardiovascular mortality in the elderly: a meta-analysis of prospective cohort studies. Medicine. 2017;96(45):e8491

84. Coons $S$, Rao $S$, Keininger D, Hays R. A comparative review of generic quality-of-life instruments. PharmacoEconomics. 2000;17(1):13-35.

85. Bakas T, McLennon S, Carpenter J, Buelow J, Otte J, Hanna K, et al. Systematic review of health-related quality of life models. Health and Quality of Life Outcomes. 2012;10(1):134.

86. Hajian-Tilaki K, Heidari B, Hajian-Tilaki A. Are gender differences in healthrelated quality of life attributable to Sociodemographic characteristics and chronic disease conditions in elderly people? Int J Prev Med. 2017;8:95.

87. Fryback GD, Dunham CN, Palta AM, Hanmer DJ, Buechner MJ, Cherepanov $G D$, et al. US norms for six generic health-related quality-of-life indexes from the National Health Measurement Study. Med Care. 2007;45(12):1162-70.

88. González-Chica D, Adams R, Dal Grande E, Avery J, Hay P, Stocks N. Lower educational level and unemployment increase the impact of cardiometabolic conditions on the quality of life: results of a populationbased study in South Australia. Qual Life Res. 2017;26(6):1521-30.

89. Frieling MA, Davis WR, Chiang G. The SF-36v2 and SF-12v2 health surveys in New Zealand: norms, scoring coefficients and cross-country comparisons. Aust N Z J Public Health. 2013;37(1):24-31.

90. Mishra G, Schofield M. Norms for the physical and mental health component summary scores of the SF-36 for young, middle-aged and older Australian women. Qual Life Res. 1998;7(3):215-20.

\section{Publisher's Note}

Springer Nature remains neutral with regard to jurisdictional claims in published maps and institutional affiliations.

Ready to submit your research? Choose BMC and benefit from:

- fast, convenient online submission

- thorough peer review by experienced researchers in your field

- rapid publication on acceptance

- support for research data, including large and complex data types

- gold Open Access which fosters wider collaboration and increased citations

- maximum visibility for your research: over $100 \mathrm{M}$ website views per year

At BMC, research is always in progress.

Learn more biomedcentral.com/submissions 